\title{
Unscrambling Words Increases Brand Name Recognition and Preference
}

\author{
ANTONIA KRONLUND ${ }^{1 *}$ and DANIEL M. BERNSTEIN ${ }^{2}$ \\ ${ }^{1}$ Simon Fraser University, Canada \\ ${ }^{2}$ Kwantlen University College, Canada and University of Washington, USA
}

\begin{abstract}
SUMMARY
Unscrambling an anagram prior to making a recognition judgement about that target word or an unrelated word increases one's claims of having seen the target word before (the revelation effect). We examined whether a revelation effect would occur with brand name recognition and preference. When participants had to solve an anagram prior to seeing a target brand, they were more likely to claim to have seen the brand before (Experiment 1), to have known the brand in high school (Experiment 2), and to give higher preference ratings for the brand (Experiments 1 and 2). These results demonstrate that the revelation effect can be applied to brand names and preference judgements. We discuss our findings in terms of discrepancy-attribution, whereby surprising fluency is misattributed to both past experience and preference. Copyright (C) 2006 John Wiley \& Sons, Ltd.
\end{abstract}

Imagine someone shopping for bottled water for the first time. What factors govern whether this consumer buys Brand X over Brand Y, in the absence of prior experience with either? In this paper, we examine the way in which other prior experiences might influence our shopper's preference for one brand over the other. To do this, we examine decisions about brand recognition and preference in the context of the revelation effect-the observation that solving a simple puzzle in the context of a memory judgement increases recognition claims. Applying the revelation effect to a consumer behaviour context is of practical importance and advances our understanding of the phenomenon in question by contributing to theory and application. Such an approach is modelled after that of Elizabeth Loftus, to whom this Special Issue is dedicated.

In a typical revelation effect experiment, participants solve an anagram of a target word (e.g. NWIDWO-WINDOW) or an unrelated word before seeing the target (e.g. NWIDWO-RAINDROP). This results in participants' increased claims of having seen the target before (Watkins \& Peynircioglu, 1990; Westerman \& Greene, 1998). The revelation effect has been observed using words (Frigo, Reas, \& LeCompte, 1999) faces (Bornstein \& Wilson, 2004) and pictures in children and adults (Guttentag \& Dunn, 2003). Although most regard the revelation effect to be limited to episodic memory tasks (e.g. Azimian-Faridani \& Wilding, 2004; Verde \& Rotello, 2004), we have shown that

*Correspondence to: Antonia Kronlund, Department of Psychology, Simon Fraser University, Burnaby, British Columbia, Canada V5A 1S6. E-mail: antonia_kronlund@sfu.ca

Contract/grant sponsor: NIMH; contract/grant number: MH642634.

Copyright (C) 2006 John Wiley \& Sons, Ltd. 
unscrambling anagrams increases one's confidence that an event occurred in one's childhood (e.g. 'broke a DWNIWO [WINDOW] playing ball') or that the answer to a trivia question is correct (e.g. fastest animal? ELPRAOD [LEOPARD]; Bernstein, Whittlesea, \& Loftus, 2002).

In the current study, we show that solving an anagram enhances one's claims of having previously seen a brand and one's preference for a brand. These findings have practical and theoretical implications for brand name recognition and preference, and for the revelation effect.

\section{EXPERIMENT 1: RECOGNITION AND PREFERENCE OF BRANDS}

The purpose of Experiment 1 was to determine whether brand name recognition and preference could be influenced by having participants solve an anagram of a word or a brand name.

\section{Method}

\section{Participants}

Fifty-two Simon Fraser University students participated for course credit in Experiment 1a; 47 in Experiment 1b.

\section{Procedures}

We chose 60 brand categories (e.g. CIGARETTES, COLA, DETERGENT, etc.) and three exemplars per category (e.g. for CIGARETTES: CAMEL, CRAVEN A, MARLBOROS). To control for prior familiarity with each brand, we used random assignment of one of the three exemplars per category per participant (i.e. 60 exemplars per participant, where participant 1 may have been assigned CRAVEN A, COKE, TIDE; participant 2 MARLBOROS, PEPSI, SUNLIGHT, etc.). Of those 60 exemplars, random assignment placed 15 exemplars into each of the following conditions: old/anagram at test, old/no anagram at test, new/anagram at test, new/no anagram at test.

For Experiment 1a, anagrams were created from 30 words chosen at random for each participant from a pool of 60 five-to-eight letter words (e.g. CANARY, AGENCY, etc.) of moderate familiarity and concreteness (obtained from the MRC Psycholinguistic Database: http://www.psy.uwa.edu.au/MRCDataBase/uwa_mrc.htm). Anagrams used in Experiment $1 \mathrm{~b}$ were brands not used elsewhere in the experiment.

Before the study phase, the experimenter told participants that they would receive a memory test following a study session, and that all items included in this phase were brands. During the study phase, a computer monitor displayed the 30 'old' brands in capital letters for $1000 \mathrm{~ms}$ each in random order for each participant.

Before the test phase began, the experimenter explained that some anagrams would appear, and that they could be solved according to a rule. The rule for the five-letter anagrams was 21435; the six-letter rule was 214356; the seven-letter rule was 2143567; the eight-letter rule was 21435678: In the five-letter anagram, AWETR, the 2 in the rule refers to the second letter in the anagram (' $W$ '), which must be placed in the first position of the solved version ( $W \ldots$. .); the 1 refers to the first letter in the anagram (' $A$ '), which comes next (i.e. WA...), and so on until the anagram is solved (WATER). The rules were available to 
participants throughout the experiment. Because of this explanation, there was a brief delay between the study and test phase.

Participants were asked to solve anagrams that appeared, to indicate whether each brand that followed the anagram was 'old' (shown during the study phase) or 'new' (not yet shown), and to make a preference rating for each brand. For the latter, the experimenter told participants that if they had never heard of the brand, they should guess; otherwise they should make their best judgement based on a comparison to other brands of a similar category, 'for example, if it's JVC, think of other brands in the electronics category such as SONY or PANASONIC and make your best judgment'. The pre-experimental familiarity with brands per se was of no interest to us, so we did not record whether participants guessed on this task.

During the test phase, a computer monitor displayed old and new target brands (in a freshly randomized order). An anagram preceded half the targets, at random. To unscramble anagrams participants entered their response on the keyboard, hitting the Return key once completed. Next, the target brand appeared on the screen and participants indicated whether it was 'old' or 'new' by pressing a button on a button box. Participants then typed their response to 'How much do you prefer this brand over a competing brand of the same category? $1=$ not at all; $7=$ very much.' The test phase was self-paced.

\section{Results and Discussion}

In both experiments, participants solved over $90 \%$ of the anagrams; subsequent analyses included solved and unsolved trials. Probabilities of claiming 'old' for Experiment 1a are depicted on the top left panel of Table 1 . These data were subjected to a $2 \times 2$ repeated measures analysis of variance (ANOVA). Overall, participants claimed to have seen more old than new items, $F(1,51)=543.73, M S E=0.03, p<0.01$, and claimed to have seen more items following an anagram than no anagram, $F(1,51)=4.19, M S E=0.01, p=0.046$.

Preference ratings for Experiment 1a are depicted on the top right panel of Table 1. These data were subjected to a repeated measures ANOVA and showed the same data pattern as found in recognition. Participants had higher preference ratings for brands seen in study, $F(1$, $51)=19.24, M S E=0.46, p<0.01$, and also had higher preference ratings for brands following an anagram as opposed to no anagram, $F(1,51)=4.72, M S E=0.22, p=0.034$.

Results of Experiment $1 \mathrm{~b}$ fully replicated those of Experiment 1a. Probabilities of claiming 'old' for Experiment $1 \mathrm{~b}$ are depicted on the bottom left panel of Table 1. These data were subjected to a $2 \times 2$ repeated measures ANOVA. Overall, participants claimed to

Table 1. Recognition and preference ratings of brands

\begin{tabular}{|c|c|c|c|c|}
\hline \multirow[t]{2}{*}{ Condition at test: } & \multicolumn{2}{|c|}{$p$ claim 'old' } & \multicolumn{2}{|c|}{ Preference ratings (out of 7) } \\
\hline & Old & New & Old & New \\
\hline \multicolumn{5}{|c|}{ Experiment 1a (Unrelated, ordinary words as anagrams): } \\
\hline No anagram & $0.77(0.02)$ & $0.19(0.03)$ & $4.29(0.13)$ & $3.95(0.13)$ \\
\hline Anagram & $0.78(0.02)$ & $0.24(0.03)$ & $4.41(0.13)$ & $4.02(0.13)$ \\
\hline \multicolumn{5}{|c|}{ Experiment $1 \mathrm{~b}$ (Unrelated brand names as anagrams): } \\
\hline No anagram & $0.76(0.02)$ & $0.19(0.02)$ & $3.88(0.13)$ & $3.57(0.10)$ \\
\hline Anagram & $0.80(0.02)$ & $0.22(0.02)$ & $3.99(0.11)$ & $3.77(0.13)$ \\
\hline
\end{tabular}

Note: Standard errors are reported in parentheses. 
have seen more old than new brands, $F(1,46)=519.89, M S E=0.03, p<0.01$, and claimed to have seen more brands following an anagram than no anagram, $F(1,46)=4.61$, $M S E=0.01, p=0.037$.

Preference ratings for Experiment $1 \mathrm{~b}$ are depicted on the bottom right panel of Table 1 . These data were subjected to a repeated measures ANOVA and showed the same data pattern as found in recognition. Participants had higher preference ratings for brands seen in study, $F(1,46)=14.94, M S E=0.22, p<0.01$, and also had higher preference ratings for brands following an anagram as opposed to no anagram, $F(1,46)=8.65, M S E=0.13, p<0.01$.

These illusions of brand name recognition and preference can be added to the growing literature on false positives in memory. Unscrambling a word or brand influences the subsequent recognition and preference of another, unrelated brand. Although the magnitude of this effect seems small, it is consistent with that found in the literature on the revelation effect. More importantly, when applied to any business venture, it would never be considered a small amount, as it translates into large-scale margins (i.e. a 3\% increase on $\$ 3,000,000$ in sales is $\$ 90,000$ ). Returning to our shopper of bottled water: These results introduce the possibility that the actual brand of water seen in the moment matters less than the decision-making processes that came immediately before seeing the bottled water. In a shopping context, this may involve processing of other brands (e.g. of a candy bar), although it may also involve the processing of ordinary words (e.g. on a store display or magazine cover).

\section{EXPERIMENT 2: BRAND RECOGNITION AND PREFERENCE WITH NO STUDY}

One may question whether these results hold in the absence of a study phase. After all, in the real world, people do not study a list of brands before shopping. Here, participants were asked to make 'confidence ratings of knowing' each brand during high school (henceforth C-ROKs) and then to make a preference rating for each brand.

\section{Method}

\section{Participants}

Twenty-five Simon Fraser University students participated for course credit. ${ }^{1}$

\section{Procedures}

The stimuli and procedures were identical to those used in Experiment 1b, with the exception that there was no study phase, and the recognition question asked, 'How confident are you that you knew this brand in high school? $1=$ not at all; $7=$ very confident'.

\section{Results and Discussion}

Participants' C-ROKs are depicted on the left side of Table 2. These data were subjected to a t-test of the difference score between the two conditions. Participants had higher C-ROKs

\footnotetext{
${ }^{1}$ The mean age of participants in Experiment 2 was 19.24 years. All participants completed high school within the past 5 years; most participants graduated in June, 2004.
} 
Table 2. Recognition and preference ratings of brands

\begin{tabular}{lcc}
\hline Experiment 2 (no study phase): & C-ROKs (out of 7) & Preference ratings (out of 7) \\
\hline No anagram & $5.35(0.18)$ & $3.84(0.19)$ \\
Anagram of unrelated brand & $5.58(0.17)$ & $4.06(0.20)$ \\
\hline
\end{tabular}

Note: Standard errors are reported in parentheses; C-ROKs are confidence ratings of knowing the brand in high school.

for brands following an anagram than no anagram, $t(24)=2.16, p=0.041$, one-tailed. Participants' preference ratings are depicted on the right side of Table 2. These data were subjected to a t-test of the difference score between the two conditions. Participants had higher preference ratings for brands following an anagram than no anagram, $t(24)=2.35$, $p=0.027$, one-tailed. Therefore, participants need not attempt to draw upon a specific episode in memory to show increased recognition and preference ratings after having solved an anagram.

\section{GENERAL DISCUSSION}

This is the first evidence to date that the revelation effect extends to brand recognition and preference: When participants had to solve an anagram prior to seeing a target brand name, they were more likely to report having seen the brand name before (Experiment 1), having known the brand in high school (Experiment 2), and to report higher preference ratings for the brand (Experiments 1 and 2).

With respect to preference judgements, two important findings emerged. First, participants preferred old to new items. This finding is consistent with work showing that repetition increases brand preference (e.g. D’Souza \& Rao, 1995; Janiszewski \& Meyvis, 2001). We believe that this increased preference is due to the fact that participants process old items more fluently (i.e. quickly) than new items (see Jacoby, Kelley, \& Dywan, 1989). Second, participants preferred brands that were preceded by an anagram. This finding, however, cannot be due to enhanced processing fluency because solving an anagram actually slows participants down (see Bernstein, Godfrey, Davison, \& Loftus, 2004; Watkins \& Peynircioglu, 1990). Thus models that use enhanced processing fluency as an explanation for increased preference ratings do not explain the present findings (e.g. Janiszewski \& Meyvis, 2001).

Most accounts of the revelation effect have centred on the assumption of activation (Cameron \& Hockley, 2000; LeCompte, 1995; Luo, 1993; Niewiadomski \& Hockley, 2001; Verde \& Rotello, 2004). The notion is that during the test phase, anagram solving causes activation of the target word or the set of studied words, creating a feeling of familiarity for the target word, which persists even if the target word follows the anagram (Westerman \& Greene, 1998). Hicks and Marsh (1998) offered an alternative explanation to activation accounts. They argued that anagrams can yield many solutions; the signal-tonoise ratio for the target word is reduced, increasing the difficulty of the recognition task. Participants respond to this increased difficulty by adopting a liberal criterion for their recognition decision (see also Azimian-Faridani \& Wilding, 2004). Niewiadomski and Hockley (2001), however, reported revelation effects of similar size regardless of whether arithmetic problems or anagrams are used. Such findings argue against Hicks and Marsh's account, which would predict lower magnitude revelation effects when using arithmetic. 
Activation and criterion shift accounts are inconsistent with research showing revelation effects in the absence of a study list (e.g. Bernstein et. al., 2002; Frigo, Reas, \& LeCompte, 1999). Further, our observation of (a) a revelation effect in a preference task immediately following a recognition judgement, and (b) a revelation effect in the absence of a study list, also fails to support criterion-shift accounts. Niewiadomski and Hockley (2001) argued that the anagram task briefly interrupts the test list, influencing only the test target (or task) immediately following the problem solving (otherwise participants would have a more liberal criterion for subsequent targets with no anagram solving). If this were the case, there would be no cause for a change in criterion for the preference task in the current work. Further, the criterion that participants use to make a recognition judgement should be different from whatever criterion they use to make a preference judgment.

Our data are more consistent with Whittlesea and Williams' (2001) discrepancyattribution account of the revelation effect. They introduced the idea that anagram solving is difficult, which causes the intact target word to be experienced as surprisingly easy or fluent. This process results in the perception of discrepancy (i.e. mismatch between initial expectation and outcome), and the accompanying feeling of familiarity is misattributed to a source in the past (see also Bernstein et al., 2002, 2004). Applied to the current work, on anagram trials, the anagram initially appears to be difficult to solve, which, in turn, leads participants to establish a local standard (e.g. GANECY - 'this is hard') ${ }^{2}$ that is offset by the surprising ease with which participants process the solution (e.g. 'oh, it's $A G E N C Y$ '). This sequential experience of expectation and surprising resolution leads to the perception of discrepancy during each anagram trial. This perception, in turn, is misattributed to having prior experience with, and enhanced preference for, the target brand that followed.

Understanding the phenomenological cognitive mechanisms that underlie brand recognition and preference is important for understanding consumer decision making, much of which occurs in the moment: when buying a snack at a vending machine (after already purchasing a soda), when walking down the aisle at a grocery store, or when choosing a gas station. In fact, in the United States, impulse buying (unplanned purchasing) reportedly generates over $\$ 4$ billion annually (Kacen \& Lee, 2002). Our findings indicate that brand presentation that involves anagram solving can enhance reports of recognition and preference. Perhaps presenting brands in a degraded fashion (e.g. as anagrams, word stems, or upside down; see Watkins \& Peynirciouglu, 1990) at store displays would create the perception of discrepancy in the moment of decision making, causing a greater likelihood of purchasing a given product. Other manipulations that capitalize on product placement (Punj \& Moon, 2002; Sayman, Hoch, \& Raju, 2002) such as logic puzzles located adjacent to the advertised product might also be fruitfully employed to this end.

\section{ACKNOWLEDGEMENTS}

D. M. B. was supported by a National Research Service Award postdoctoral fellowship from NIMH (MH642634). This research was conducted while A. K. was at Simon Fraser University. She is now at the Department of Marketing, International Business and Strategy, Faculty of Business, Brock University, St. Catharines, ON, Canada, L2S 3A1. We thank Aleksandra Waliszewska, Mara Billings, and Leanne Wagner for their help with ${ }^{2}$ Perhaps this is because participants automatically processed the anagram (e.g. GA-NE-CY: 'GA-NE-SEE'),
making it appear difficult to solve. 
data collection on this project. We thank Maryanne Garry, Deryn Strange, Matt Gerrie, Melanie Takarangi, and Lauren Strange, for very helpful comments on an earlier draft of this paper.

\section{REFERENCES}

Azimian-Faridani, N., \& Wilding, E. L. (2004). An event-related potential study of the revelation effect. Psychonomic Bulletin \& Review, 11, 926-931.

Bernstein, D. M., Godfrey, R. D., Davison, A., \& Loftus, E. (2004). Conditions affecting the revelation effect for autobiographical memory. Memory \& Cognition, 32, 455-462.

Bernstein, D. M., Whittlesea, B. W. A., \& Loftus, E. F. (2002). Increasing confidence in remote autobiographical memory and general knowledge: extensions of the revelation effect. Memory \& Cognition, 30, 432-438.

Bornstein, B. H., \& Wilson, J. R. (2004). Extending the revelation effect to faces: haven't we met before? Memory, 12, 140-146.

Cameron, T. E., \& Hockley, W. E. (2000). The revelation effect for item and associative recognition: familiarity versus recollection. Memory \& Cognition, 28, 176-183.

D'Souza, G., \& Rao, R. C. (1995). Can repeating an advertisement more frequently than the competition affect brand preference in a mature market? Journal of Marketing, 59, 32-42.

Frigo, L. C., Reas, D. L., \& LeCompte, D. C. (1999). Revelation without presentation: counterfeit study list yields robust revelation effect. Memory \& Cognition, 27, 339-343.

Guttentag, R., \& Dunn, J. (2003). Judgments of remembering: the revelation effect in children and adults. Journal of Experimental Child Psychology, 86, 153-167.

Hicks, J. L., \& Marsh, R. L. (1998). A decrement-to-familiarity interpretation of the revelation effect from forced-choice tests of recognition memory. Journal of Experimental Psychology: Learning, Memory, and Cognition, 24, 1105-1120.

Jacoby, L. L., Kelley, C. M., \& Dywan, J. (1989). Memory attributions. In H. I. Roediger, \& F. I. M.Craik (Eds.), Varieties of memory and consciousness: Essays in honor of Endel Tulving (pp. 391-422). Hillsdale, NJ: Erlbaum.

Janiszewski, C., \& Meyvis, T. (2001). Effects of brand logo complexity, repetition, and spacing on processing fluency and judgment. Journal of Consumer Research, 28, 18-32.

Kacen, J. L., \& Lee, J. A. (2002). The influence of culture on consumer impulsive buying behavior. Journal of Consumer Psychology, 12, 163-176.

LeCompte, D. C. (1995). Recollective experience in the revelation effect: separating the contributions of recollection and familiarity. Memory \& Cognition, 23, 324-334.

Luo, R. (1993). Enhanced feeling of recognition: effect of identifying and manipulating test items on recognition memory. Journal of Experimental Psychology: Learning, Memory, and Cognition, 19, 405-413.

Niewiadomski, M., \& Hockley, W. E. (2001). Interrupting recognition memory: tests of familiaritybased accounts of the revelation effect. Memory \& Cognition, 29, 1130-1138.

Punj, G., \& Moon, J. (2002). Positioning options for achieving brand association: a psychological categorization framework. Journal of Business Research, 55, 275-283.

Sayman, S., Hoch, S. J., Raju, J. S. (2002). Positioning of store brands. Marketing Science, 21, 378397.

Verde, M. F., \& Rotello, C. M. (2004). ROC curves show that the revelation effect is not a single phenomenon. Psychonomic Bulletin \& Review, 11, 560-566.

Watkins, M. J., \& Peynircioglu, Z. F. (1990). The revelation effect: when disguising test items induces recognition. Journal of Experimental Psychology: Learning, Memory, and Cognition, 16, 10121020.

Westerman, D. L., \& Greene, R. L. (1998). The revelation that the revelation effect is not due to revelation. Journal of Experimental Psychology: Learning, Memory, and Cognition, 24, 377-386.

Whittlesea, B. W. A., \& Williams, L. D. (2001). The discrepancy-attribution hypothesis: I. The heuristic basis of feelings of familiarity. Journal of Experimental Psychology: Learning, Memory, and Cognition, 27, 3-13. 